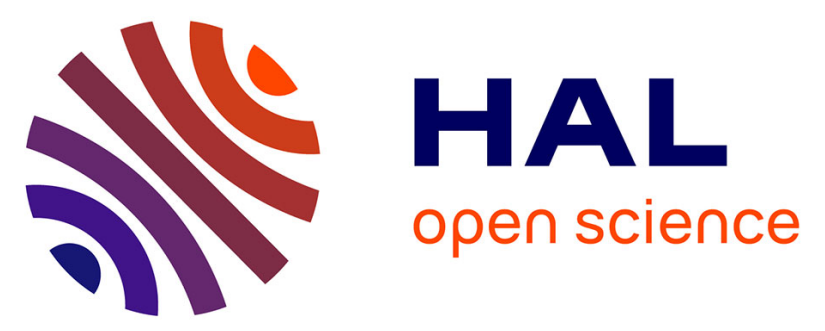

\title{
Correlations between microbial population dynamics, bamA gene abundance and performance of anaerobic sequencing batch reactor (ASBR) treating increasing concentrations of phenol
}

\author{
Oscar Franchi, Léa Cabrol, Rolando Chamy, Francisca Rosenkranz
}

\section{To cite this version:}

Oscar Franchi, Léa Cabrol, Rolando Chamy, Francisca Rosenkranz. Correlations between microbial population dynamics, bamA gene abundance and performance of anaerobic sequencing batch reactor (ASBR) treating increasing concentrations of phenol. Journal of Biotechnology, 2020, 310, pp.40-48. 10.1016/j.jbiotec.2020.01.010 . hal-03147119

\section{HAL Id: hal-03147119 \\ https://hal-amu.archives-ouvertes.fr/hal-03147119}

Submitted on 22 Mar 2021

HAL is a multi-disciplinary open access archive for the deposit and dissemination of scientific research documents, whether they are published or not. The documents may come from teaching and research institutions in France or abroad, or from public or private research centers.
L'archive ouverte pluridisciplinaire HAL, est destinée au dépôt et à la diffusion de documents scientifiques de niveau recherche, publiés ou non, émanant des établissements d'enseignement et de recherche français ou étrangers, des laboratoires publics ou privés.

\section{(ㅇ)(1) $\$$}

Distributed under a Creative Commons Attribution - NonCommercial - NoDerivatives 44.0 


\title{
Correlations between microbial population dynamics, bamA gene abundance and performance of anaerobic sequencing batch reactor (ASBR) treating increasing concentrations of phenol
}

\author{
Oscar Franchi $^{\mathrm{a}, *}$, Léa Cabrol ${ }^{\mathrm{b}}$, Rolando Chamy $^{\mathrm{a}, \mathrm{c}}$, Francisca Rosenkranz $^{\mathrm{c}}$ \\ ${ }^{a}$ Escuela de Ingeniería Bioquímica, Pontificia Universidad Católica de Valparaíso, Avenida Brasil 2085, Valparaíso, Chile \\ ${ }^{\mathrm{b}}$ Aix Marseille Univ, Univ Toulon, CNRS, IRD - Mediterranean Institute of Oceanography (MIO - UM 110), Marseille, France \\ ${ }^{\mathrm{c}}$ Núcleo Biotecnología Curauma, Pontificia Universidad Católica de Valparaíso, Avenida Universidad 330, Valparaíso, Chile
}

A R T I C L E I N F O

\section{Keywords:}

Anaerobic digestion

bamA gene

Illumina sequencing

Microbial community

Phenol

\begin{abstract}
A B S T R A C T
The relevant microorganims driving efficiency changes in anaerobic digestion of phenol remains uncertain. In this study correlations were established between microbial population and the process performance in an anaerobic sequencing batch reactor (ASBR) treating increasing concentrations of phenol (from 120 to $1200 \mathrm{mg}$ $\mathrm{L}^{-1}$ ). Sludge samples were taken at different operational stages and microbial community dynamics was analyzed by $16 \mathrm{~S}$ rRNA sequencing. In addition, bamA gene was quantified in order to evaluate the dynamics of anaerobic aromatic degraders. The microbial community was dominated by Anaerolineae, Bacteroidia, Clostridia, and Methanobacteria classes. Correlation analysis between bamA gene copy number and phenol concentration were highly significant, suggesting that the increase of aromatic degraders targeted by bamA assay was due to an increase in the amount of phenol degraded over time. The incremental phenol concentration affected hydrogenotrophic archaea triggering a linear decrease of Methanobacterium and the growth of Methanobrevibacter. The best performance in the reactor was at $800 \mathrm{mg} \mathrm{L}^{-1}$ of phenol. At this stage, the highest relative abundances of Syntrophorhabdus, Chloroflexus, Smithella, Methanolinea and Methanosaeta were observed and correlated positively with initial degradation rate, suggesting that these microorganisms are relevant players to maintain a good performance in the ASBR.
\end{abstract}

\section{Introduction}

Phenol is a widespread compound present in many industrial effluents such as coal conversion processes, petroleum refineries, herbicide manufacturing and petrochemicals. The concentration of phenolic compounds in this kind of effluents varies from 10 to $17,000 \mathrm{mg} \mathrm{L}^{-1}$ contributing to $40-80 \%$ of its total chemical oxygen demand (COD) (Veeresh et al., 2005).

To treat effluents containing phenol, several physicochemical and biological treatments are available. Among biological processes, different anaerobic technologies that work with biomass retention such as upflow anaerobic sludge blanket reactor (UASB), expanded granular sludge bed reactor (EGSB) and anaerobic sequencing batch reactor (ASBR) have been implemented to cope with the presence of phenol. The advantages that these anaerobic systems offer compared to other biological technologies are: high organic loading rates capacity; methane production; low sludge generation and the capability of retaining microbes with special functions (e.g. phenolic compounds degradation) (Almendariz et al., 2005; Veeresh et al., 2005; Rosenkranz et al., 2013).

Due to the antimicrobial properties of phenol, this compound is toxic and inhibitory for most microorganisms (Chen et al., 2008a). In anaerobic sludge, half-maximal effective concentrations $\left(\mathrm{EC}_{50}\right)$ are reported to be between 120 and $225 \mathrm{mg} \mathrm{gVS}^{-1}$ (Hernandez and Edyvean, 2008; Wirth et al., 2015). Either in a phenol-acclimated and non-acclimated sludge, increasing concentrations of this compound affects the anaerobic digestion performance, deteriorating both the removal efficiency and methane production rate (Fang et al., 2004; Chapleur et al., 2016). According to this, the identification of the microbial populations resistant to high phenol concentrations is relevant to design and establish operational strategies capable to maintain such microbial members in order to improve the system's stability. In line with this, one of the final goals of the microbial community studies in anaerobic digestion systems is to find the relationship between specific microorganims dynamics and system's performance in order to determine if

\footnotetext{
* Corresponding author.

E-mail address: oscar.franchi.m@mail.pucv.cl (O. Franchi).
} 
Table 1

Operational parameters and performance indicators of the phenol-fed ASBR reactor under the five operational stages.

\begin{tabular}{|c|c|c|c|c|c|}
\hline Stage & $\mathbf{I}$ & II & III & IV & $\mathbf{V}$ \\
\hline Inlet phenol concentration $\left[\mathrm{mg} \mathrm{L}^{-1}\right]$ & $120 \pm 60$ & $240 \pm 4$ & $500 \pm 50$ & $800 \pm 7$ & $1200 \pm 43$ \\
\hline Initial degradation rate $\left(\mathrm{mg}\right.$ phenol $\left.\cdot \mathrm{VSS}^{-1} \cdot \mathrm{d}^{-1}\right)$ & 10 & 11 & 13 & 15 & 13 \\
\hline Elimination capacity $\left(\mathrm{mg}\right.$ phenol $\cdot \mathrm{VSS}^{-1} \cdot \mathrm{d}^{-1}$ ) & 26 & 28 & 19 & 31 & 11 \\
\hline Degradation time of last cycle (h) & 13 & 20 & 45 & 50 & 215 \\
\hline Operational time (d) /number of cycles & $39 / 22$ & $18 / 7$ & $21 / 6$ & $33 / 7$ & $85 / 6$ \\
\hline
\end{tabular}

this relationship could be useful to establish performance biomarkers that serves as early warning indicators of process failure or performance enhancement (Carballa et al., 2015).

Molecular approaches such as DNA fingerprinting and sequencing methods have been used to unravel relationships between microbial community dynamics and performance changes under variable phenol concentrations (Fang et al., 2004; Rosenkranz et al., 2013; Wirth et al., 2015; Chapleur et al., 2016; Madigou et al., 2016). In all these studies, the results show that Clostridiales is a highly abundant order during anaerobic digestion of this compound, together with -in some casesAnaerolinaceae and Syntrophaceae (Rosenkranz et al., 2013; Wirth et al., 2015), suggesting that they play an important role in the process. However, the identification of high abundant microorganisms in the process not necessarily implies high activity from them (De Vrieze et al., 2016) and low abundance populations could even be more active than the most abundant ones, as demonstrated by metatranscriptomic and metaproteomic methods (Zakrzewski et al., 2012; Hanreich et al., 2013).

For this reason, a robust statistical analysis of the microbial community abundance dynamics must be done to establish which microorganisms are significantly correlated with a particular performance parameter of the process. Pearson correlation analysis tests have been used to identify key microbial players driving the performance/efficiency of anaerobic digesters (Regueiro et al., 2015; Shin et al., 2016). Regarding anaerobic digestion process of phenol, a correlation analysis between changes in the abundance of certain microorganisms and the performance of the reactor is still lacking.

Even though the sequencing analysis of microbial communities by 16S rRNA gene display more accurate results than fingerprinting methods (for example, DGGE band sequencing) (Pylro et al., 2016) this analysis also has some limitations due that the identity of microorganisms depends on reported sequences within databases. Because of that, it is recomendable to complement this information by studying functional genes (Oka et al., 2011).

In the anaerobic degradation pathway of phenol this compound is first oxidized to benzoate, which is then activated and converted to benzoyl-coA by benzoyl-CoA ligase. This intermediate compound is dearomatized by the benzoyl-CoA reductase to form cyclohex-1,5diene-1-carbonyl-CoA. The oxidation of this product follows a kind of beta-oxidation, which includes a hydrolytic opening of the alicyclic ring which is mediated by the 6-oxocyclohex-1-ene-1-carbonyl-CoA hydrolase. The product of this cleavage follows $\beta$-oxidation reactions to produce acetate (Levén et al., 2012; Fuchs, 2008). The bamA gene for example codifies the hydrolase which catalyse the ring cleavage step of 6-oxocylcohex-1-ene-1-carbonyl-CoA during the anaerobic degradation of phenol via the 4-hydroxybenzoate to benzoyl-CoA pathway (Kuntze et al., 2008, 2011; Laempe et al., 1999). This gene has been used as a biomarker of aromatic-degrading anaerobes and has been correlated positively with the amount of degraded mono aromatic compounds (Sun et al., 2014). Therefore, the study of the bamA gene dynamics in the anaerobic digestion process of phenol is an interesting approach to estimate the abundance of anaerobes effectively involved in the degradation of this compound.

In this context, the present work aims at studying the microbial community dynamics of an anaerobic sequencing batch reactor (ASBR) treating increasing phenol concentrations, and to assess the potential correlations between reactor performance parameters and abundances of specific phylotypes within the sludge community in order to find potential performance biomarkers within the process. The microbial community was analyzed both at the total diversity level by a taxonomic approach (through next-generation sequencing of 16S rRNA gene by Illumina MiSeq) and at the functional population level by targeting anaerobic phenol-degraders (through bamA gene quantification).

\section{Material and methods}

\subsection{Experimental set-up}

A $5 \mathrm{~L}$ laboratory-scale ASBR was operated using a granular sludge inoculum from a tobacco waste water treatment plant at $12 \mathrm{~g}$ of volatile suspended solids per liter (VSS $\mathrm{L}^{-1}$ ), as previously described in Rosenkranz et al. (2013). Biomass concentration was kept approximately constant by doing sludge purges, every two weeks. The reactor was operated at $37{ }^{\circ} \mathrm{C}$ and fed with synthetic wastewater containing phenol (Sigma-Aldrich, 99\%) as the sole carbon source and $21.4 \mathrm{mg}$ $\mathrm{L}^{-1}$ of $\mathrm{KH}_{2} \mathrm{PO}_{4}, 4.3 \mathrm{mg} \mathrm{L}{ }^{-1}$ of $\mathrm{NH}_{4} \mathrm{Cl}$ and $\mathrm{NaHCO}_{3}$ to maintain alkalinity in a range of 2.5-3.0 $\mathrm{g} \mathrm{CaCO}_{3} \mathrm{~L}^{-1}$. Each cycle of ASBR operation is constituted of 4 steps: feeding ( $20 \mathrm{~min}$ ), reaction (the time needed to degrade at least $90 \%$ of phenol), biomass settling $(1 \mathrm{~h})$ and effluent discharge $(20 \mathrm{~min})$. The volume exchange ratio was $60 \%$. After an initial acclimation to phenol at $120-240 \mathrm{mg} \mathrm{L}^{-1}$ that lasted 80 days (22 cycles), the inlet phenol concentration was progressively increased from 120 to $1200 \mathrm{mg} \mathrm{L}^{-1}$ during five operational stages (I to V), as described in Table 1.

\subsection{Analytical methods}

Volatile suspended solids were measured according to Standard Methods (APHA, 1995). Phenol was detected and quantified by a gas chromatograph GC-8A (Shimadzu, Kyoto, Japan), equipped with a 30"x4 mm ID packed column GP 60/80 Carbopack C/0.3\% Carbowax $20 \mathrm{M} / 0.1 \% \mathrm{H}_{3} \mathrm{PO}_{4}$ (Sigma Aldrich, St Louis, MO, US). The analysis was carried out at $120^{\circ} \mathrm{C}$, using nitrogen as carrier gas $(50 \mathrm{~mL} / \mathrm{min})$ and a flame ionization detector at $200{ }^{\circ} \mathrm{C}$.

\subsection{Performance evaluation}

All the following performance indicators excepting the elimination capacity (EC) were calculated during the last cycle of operation at each stage, once the degradation time got stabilized thus indicating the adaptation of the process to each concentration step. The EC was calculated as the total degraded phenol amount divided by the total degradation time over the entire stage, relative to the biomass content (mg phenol $\mathrm{g}^{-1} \mathrm{VSS}^{-1} \mathrm{~L}^{-1} \mathrm{D}^{-1}$ ). The initial phenol degradation rate (IDR) was calculated as the slope of the first linear region of the degradation profiles and degradation time (DT) was defined as the time required to degrade at least $90 \%$ of inlet phenol during the last cycle of the stage. 


\subsection{DNA extraction}

The DNA extracts for this research were obtained from a previous study from our lab (Rosenkranz et al., 2013). At that moment the extracts were aliquoted in sterile DNAse free microtubes and stored at $-80{ }^{\circ} \mathrm{C}$ for the $16 \mathrm{~S}$ rRNA gene sequencing analysis and quantitative PCR assay (for this study). Briefly, in each stage of operation, sludge samples were collected at the end of the last cycle of operation, once phenol degradation efficiency reached at least $90 \%$. Sludge samples were centrifuged at $10,000 \mathrm{~g}$ for $10 \mathrm{~min}$ and $0.5 \mathrm{~g}$ of pellet obtained were used for DNA extraction using the Powersoil DNA Isolation Kit (MO BIO Laboratories) following the manufacturer's instructions. The integrity of DNA extracts was checked by $2 \%$ agarose gel electrophoresis. DNA concentration and purity were tested by UV spectrophotometric analysis at 260, 280 and $230 \mathrm{~nm}$ using a Nanodrop (Shimadzu Bio Spec-nano).

\subsection{Quantitative PCR ( $q P C R)$}

The quantification assays were conducted in an AriaMX real-time PCR cycler (Agilent). Total bacteria and archaea abundances were assayed using the protocol described by Yu et al. (2006). The bamA gene quantification was performed using the primer set Bam-sp9 and Bamasp1 targeting a 300 bp fragment (Kuntze et al., 2008). Each 20 u L PCR reaction contained $10 \mathrm{u} \mathrm{L}$ of Takyon Rox SYBR MasterMix dTTP Blue (Eurogentec, Köln, Germany), $0.9 \mathrm{u} \mathrm{M}$ of each primer and $2 \mathrm{u} \mathrm{L}$ of ten fold diluted DNA template. The thermal program consisted of an initial denaturation $\left(95{ }^{\circ} \mathrm{C}, 3 \mathrm{~min}\right)$ and 44 amplification cycles $\left(95^{\circ} \mathrm{C}\right.$ for $3 \mathrm{~s}$; $60{ }^{\circ} \mathrm{C}$ for $40 \mathrm{~s}$ ). Melting curves were constructed from $65{ }^{\circ} \mathrm{C}$ to $95{ }^{\circ} \mathrm{C}$, read every $0.5^{\circ} \mathrm{C}$ for $5 \mathrm{~s}$. Calibration curves of bamA gene $\left(10^{\circ}-10^{6}\right.$ gene copies/uL) were prepared using genomic DNA from the anaerobic phenol-degrader Thauera aromatica (DSM 6984) assuming a genome size of 4.6 Mb (Kazy et al., 2010) and one copy number of this gene per genome. Quantification was carried out on triplicate samples. The qPCR efficiencies for all reactions were between $90-100 \%$. The results were expressed in gene copy number per gram of wet weight of sludge.

\section{6. $16 S$ rRNA amplicon gene sequencing}

DNA samples were sequenced targeting the V4-V5 hyper variable region of the 16S rRNA gene with primers $515 \mathrm{~F}$ and 909R targeting both bacterial and archaeal communities (Wang and Qian, 2009). Sequencing was performed at MR DNA laboratory (Shallowater, TX, USA) on a MiSeq Illumina sequencer following the manufacturer's guidelines. Sequence data were processed using a proprietary analysis pipeline (MR DNA, Shallowater, TX, USA). In summary, sequences were joined, depleted of barcodes then sequences $<150$ bp removed, sequences with ambiguous base calls removed. Sequences were denoised, OTUs generated and chimeras removed. Operational taxonomic units (OTUs) were defined by clustering at $3 \%$ divergence ( $97 \%$ similarity). Final OTUs (Online Resource 1) were taxonomically classified using BLASTn against a curated GreenGenes database (DeSantis et al., 2006).

\subsection{Statistical analysis of microbial community}

Microbial community structure and correlation analysis between microbial populations and performance parameters at different stages of the reactor were computed with XLSTAT version 2014 (Addin soft). Beta diversity analysis of microbial community at different operational stages of reactor was carry out using the agglomerative hierarchical clustering (AHC) method, based on the relative abundances profiles of microorganisms at genus level (Eichorst et al., 2013). A dendrogram resulting from the AHC analysis was constructed using the mean link agglomeration method and the Bray-Curtis dissimilarity distance which quantifies how dissimilar a pair of samples is, based on specimen counts (Wong et al., 2016). Heat-map of genus dynamics over the different operational stages was performed within the Heat-map tool. Principal component analysis (PCA) was performed using the data analysis tool using the option Pearson correlation type and was constructed in order to visualize community structure distribution under different phenol concentrations and its effects on 3 performance parameters: initial degradation rate (IDR), elimination capacity (EC) and degradation time (DT). BamA gene abundance was also included as a biological variable in the PCA plot. Significant correlations between genus abundances, environmental and performance parameters together with bamA gene abundance were determined by Pearson correlation test analysis. The results from a Pearson correlation test having a p-value $\leq 0.05$ were considered as significant.

\section{Results and discussion}

\subsection{Effect of increasing phenol concentrations on process performance}

After an acclimation period of 80 days, phenol concentration feeding in the ASBR was increased stepwise from $120 \pm 60$ up to $1200 \pm 43 \mathrm{mg} \mathrm{L}^{-1}$ in a total process that was divided in five operational stages (Table 1). The detailed analysis of process performance in response to phenol increase was described previously (Rosenkranz et al., 2013) and the most relevant indicators of the process were used in this study to enlighten relationships with the microbial community structure and composition revealed by the $16 \mathrm{~S}$ rRNA gene sequencing analysis. Briefly, the total degradation time (DT) necessary to degrade $90 \%$ of the compound increased continuously as a result of higher substrate load. DT increase was linear during the first three stages (Table 1), got rather stable during Stage IV, and drastically increased during stage $\mathrm{V}$ (more than four times compared to the previous stage). As a result, the Elimination Capacity (EC) remained relatively constant (around $26 \mathrm{mg}$ phenol. $\mathrm{VSS}^{-1} \cdot \mathrm{d}^{-1}$ ) from Stage I to IV, and dropped down to $11 \mathrm{mg}$ phenol $\cdot \mathrm{VSS}^{-1} \cdot \mathrm{d}^{-1}$ in Stage V. Within each degradation profile, the Initial Degradation Rate (IDR) is indicative of the capacity of the community to withstand a new charge load. It increased progressively during the first four stages, and then decreased in the last stage. All together, these indicators show a maximal degradation efficiency at $800 \mathrm{mg} \mathrm{L}^{-1}$ of phenol (Stage IV) and suggest the existence of a threshold concentration between 800 and $1200 \mathrm{mg} \mathrm{L}^{-1}$ after which the reaction rate slowdowned, evidencing a deterioration of the reactor performance and possible partial inhibition.

Other studies performed in batch assays under methanogenic conditions reported a complete inhibition of phenol degradation at 2000 $\mathrm{mg} \mathrm{L}^{-1}$ (Poirier et al., 2016; Chapleur et al., 2016). In our case, the maximal concentration applied $\left(1200 \mathrm{mg} \mathrm{L}^{-1}\right)$ was below the complete inhibition limit: the degradation rate of the reactor is impaired but the adapted anaerobic biomass due to reactor configuration (ASBR) could tolerate and metabolize this load.

\subsection{Total bacterial and archaeal abundances}

As can be seen in Fig. 1A, the Bacteria and Archaea in this system represent on average $70 \%$ and $30 \%$, respectively of the total community during the whole period, which is consistent with the operating conditions favoring favouring methanogenic activity. Despite reactor performance was negatively affected at the highest phenol concentration there was only a small decrease in total bacteria and archaea abundances only at Stage II (which was rapidly recovered at the subsequent stage), total microbial abundance stayed rather constant along the operation, independently of the phenol concentration, suggesting that the toxic phenol threshold implying mortality was not reached and that performance impairement was due to a change in microbial structure configuration rather than biomass losses. 

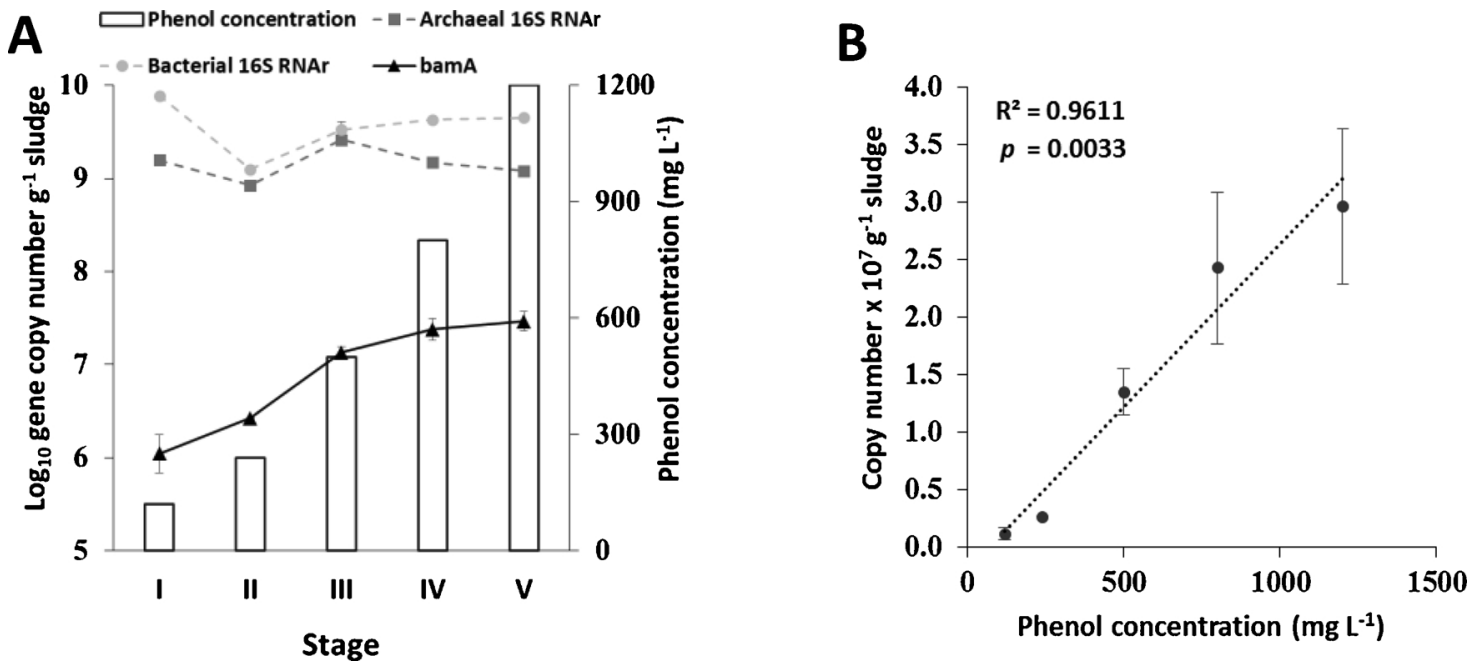

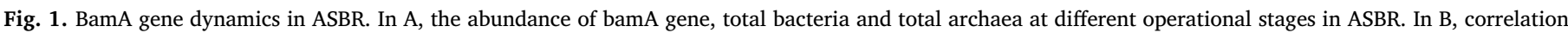

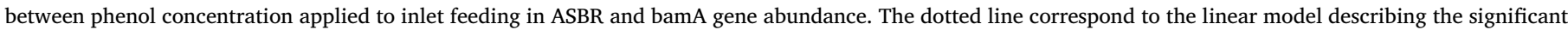
correlation between variables. Error bars represents one standard deviation arround the mean.

\subsection{Evolution of bamA gene abundance at different ASBR stages}

During the ASBR process the bamA gene levels had an incremental trend as phenol concentration increase (Fig. 1A), suggesting that microorganisms with the capacity to degrade phenol accumulated throughout the process. In our work, phenol is removed through the process and bamA levels increased in a significant positive linear correlation $(\mathrm{p}<0.01)$ with phenol concentration (Fig. 1B). Inlet phenol concentration is therefore a strong and direct selective pressure/driving force stimulating the growth of phenol-degraders.

The bamA gene copy number was 2-4 orders of magnitude lower than the total bacterial and archaeal 16SrRNA gene copy number, confirming that the functional community effectively involved in phenol degradation via the benzoyl-CoA pathway represents only a minor fraction $(0.3 \%$ maximum) of the total community. Variations in 16S rRNA gene copy number per genome between microorganisms also could originate an underestimation of the relative abundance of bamA gene harbouring populations. This result demonstrates the importance to consider the rare biosphere in anaerobic digestion ecosystems, where subdominant species can act as keystones and impact the overall function despite their low abundance, as highlighted in fermentative ecosystems (Rafrafi et al., 2013).

There is only one study that employed bamA gene quantification to enumerate anaerobic aromatic degraders under methanogenic conditionns and that suggest a correlation between the increase of bamA gene levels and the removal percentage of an aromatic compound (toluene) (Sun et al., 2014). Based on this, our result confirms that quantification of bamA gene could be useful as a monitoring variable capable of describe the progression of degradation process of mono aromatic compounds.

\subsection{Microbial community analysis}

\subsubsection{Effect of phenol concentration at overall microbial community} structure in ASBR

Within Bacteria, Miseq amplicon sequencing analysis shows that Anaerolineae, Bacteroidia, Clostridia and Deltaproteobacteria were the dominant bacterial classes in almost all operational stages, except for Stage I (Fig. 2), where Alphaproteobacteria and Bacilli were dominant at the expense of Deltaproteobacteria abundance. The Bacteroidia and Clostridia classes have been reported as dominant in anaerobic batch reactors treating phenol as the sole carbon source at different concentrations (Wirth et al., 2015). The Deltaproteobacteria class has been

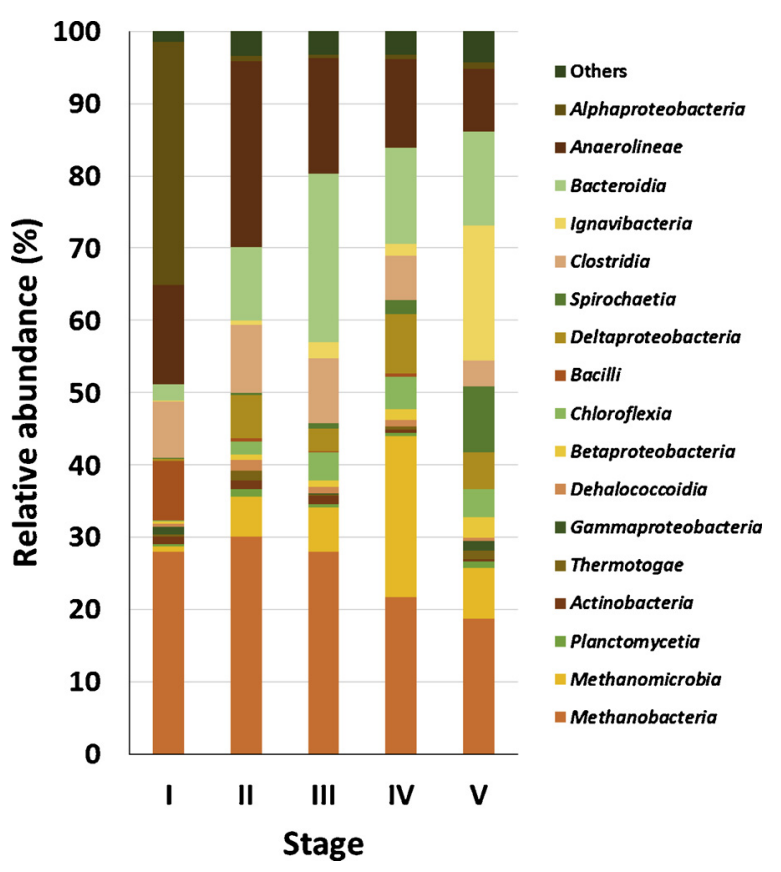

Fig. 2. Relative abundance at class level of microbial communities in the ASBR at the last cycle of each operational stage. Only classes having abundance $\geq 1 \%$ in at least one sample are represented otherwise were considered as "others".

found dominant in mesophilic methanogenic phenol degrading enrichments at $500 \mathrm{mg} \mathrm{L}^{-1}$ (Chen et al., 2008b). Anaerolineae, on the other hand, is regarded as an important class from the Chloroflexi phylum, which is part of the "core group" of organisms always found in anaerobic digesters independently of substrate nature (Cabezas et al., 2015).

Within the archaeal domain, Methanobacteria was the dominant class in all operational stages followed by Methanomicrobia. According to these results, it is likely that anaerobic digestion of phenol in this system was carried out mainly via the hydrogenotrophic methanogenesis pathway.

\subsubsection{Structural changes at genus level during ASBR operation}

Fig. 3B shows the AHC analysis of microbial community profiles at the genus level (only those with abundances equal or over $0.5 \%$ in at 
(A) Bray-Curtis Dissimilarity

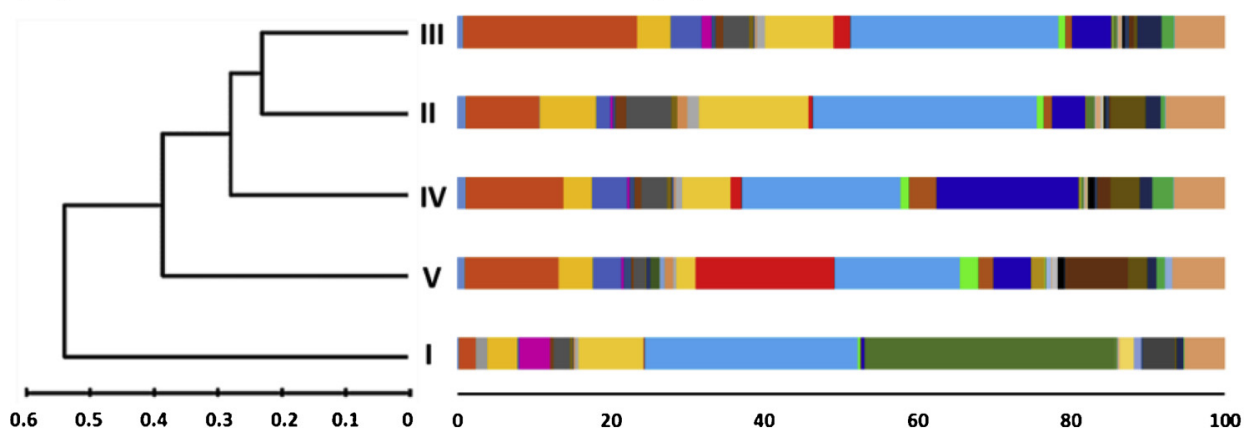

Fig. 3. Microbial community structure at the genus level in ASBR operating at different feeding phenol concentrations $(\mathrm{I}=120$, II $=$ 240 , III $=500$, IV $=800$ and $\mathrm{V}=1200 \mathrm{mg} \mathrm{L}$ 1). In A, community clustering analysis based on Bray-Curtis dissimilarity between samples. In $\mathrm{B}$, relative abundance of genera at each stage. Only genera having abundance $\geq 0.5 \%$ in at least one sample are represented otherwise were considered as "others".

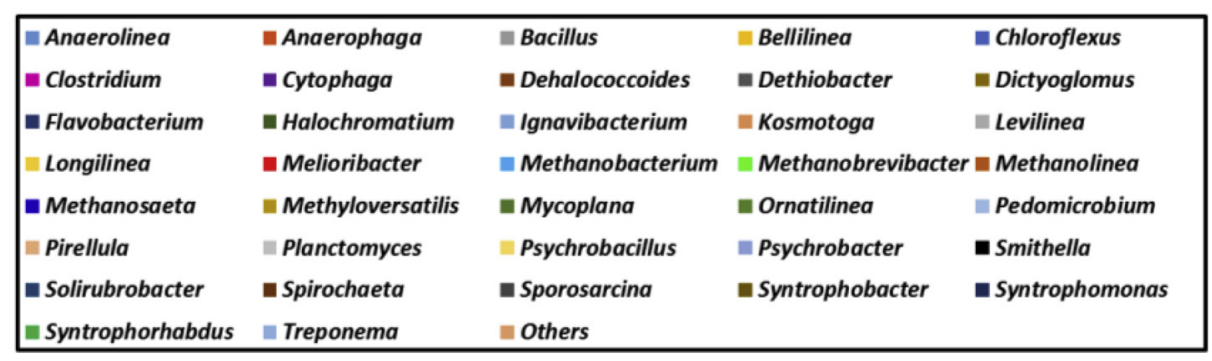

least one sample) and the relative abundances of each genus at different operational stages in ASBR. The dendrogram (Fig. 3A) shows the strongest differentiation between community from stage I (corresponding to the lowest phenol concentration at $120 \mathrm{mg} \mathrm{L}^{-1}$ ) and the other stages, highlighting the sludge acclimatation process to new environmental conditions imposed by phenol feeding. This differentiation was caused mainly by the highest relative abundance of Mycoplana which dominated the bacterial community (33\% of total bacteria), as well as the presence of Clostridium (4\%) and Sporosarcina (4\%), while they were all almost negligible in the following stages (Fig. 4B). As far as we know, this is the first report of Mycoplana presence in an anaerobic digester treating phenol. The capacity of Mycoplana to degrade aromatic compounds has been reported previously in pure culture experiments (Lakshmi et al., 2013) and was found at low abundance levels in a microcosm treating nonylphenol at $100 \mathrm{ppm}$ under nitrate reducing conditions (Wang et al., 2015). Thus, Mycoplana was presumably the main phenol degrader at this stage, followed by Clostridium and Sporosarcina, which have been reported at high abundance in methanogenic reactors treating phenolic compounds (Tartakovsky et al., 2001; Hernandez et al., 2013). The drastical decrease of Mycoplana at the following stages suggest that this genus is not adapted to growth efficiently at higher phenol concentrations under methanogenic conditions.

Regarding dominant archaeal genera, Methanobacterium (an hydrogenotrophic methanogen) was the most abundant followed by Methanosaeta (acetotrophic) and Methanolinea (hydrogenotrophic). Methanobacterium dominance, in anaerobic digestion of phenol, has been reported previously (Madigou et al., 2016), but its high abundance is not a necessary requirement to carry out the process efficiently, since other studies involving phenol degradation reported that Methanosaeta, Methanosarcina and Methanoculleus can be dominant too (Poirier et al., 2016; Zhang et al., 2005).

After Stage I, the community structure followed a clear progressive evolution along the phenol concentration gradient applied (between 240 and $1200 \mathrm{mg} \mathrm{L}^{-1}$ ), as evidenced in the dendrogram representation, where the successive stages cluster together. Within this group, the medium-concentration samples (between 240 and $800 \mathrm{mg} \mathrm{L}^{-1}$ ) clustered together (at $\sim 70 \%$ of similarity), clearly apart from stage $\mathrm{V}$ sample, in which the highest concentration of phenol was applied. This last stage is characterized by the highest abundance of Melioribacter (18\%) (which dominated the community), and the presence of Spirochaeta, Methyloversatilis and Methanobrevibacter, in contrast with the previous stages where they were almost negligible, suggesting that these genera were able to tolerate phenol concentration as high as 1200 $\mathrm{mg} \mathrm{L}^{-1}$. Within these genera, Methyloversatilis is the only microorganism capable of metabolizing phenol (Smalley et al., 2015). Melioribacter and Spirochaeta on the other hand, were reported to be present in methanogenic systems treating aromatic compounds but their effective role in phenol degradation is not clear (Li et al., 2014; Xiong et al., 2015). Within all archaeal members, Methanobrevibacter was the only genus that had its maximum abundance at this stage indicating that this hydrogenotrophic methanogen can growth better than other methanogens under this environmental condition.

At stage IV, in which performance of ASBR was better, Methanosaeta and Methanolinea were the methanogens that showed their highest abundance (19 and $4 \%$, respectively) in comparison to other stages as can been seen in the heat-map (Fig. 5). Methanosaeta is a well-known microorganism that produces methane via the acetotrophic pathway (Smith and Ingram-Smith, 2007). This genus probably uses the acetate generated from phenol conversion by direct phenol or benzoate degraders. Regarding bacterial members, the genera that had their highest abundance value at this stage (compared to the other stages) were Smithella, Syntrophorhabbdus and Chloroflexus $(0.9,2.7$ and 4.6\%, respectively) as can be seen in the heat-map (Fig. 5). From those, Syntrophorhabdus is the only known phenol degrader that acts in syntrophy with a hydrogen scavenger microorganism to grow (Qiu et al., 2008). Based on this, the highest abundance of the syntrophic phenol degrader Syntrophorhabdus coupled to a greater abundance of the hydrogenotrophic methanogen Methanolinea could be the reason of the increase in phenol degradation performance at this stage. An increase in phenol degradation must lead to an increment on acetate production rate, which would explain the greater abundance of Methanosaeta.

\subsubsection{Identification and dynamics of core community}

The analysis of the microbial populations also allowed us to establish a group of genera that maintained relative abundances of at least $2 \%$ in all operational stages, which implies that they can be of great importance to carry out the process successfully. This group was formed 


\section{Relative abundance (\%)}
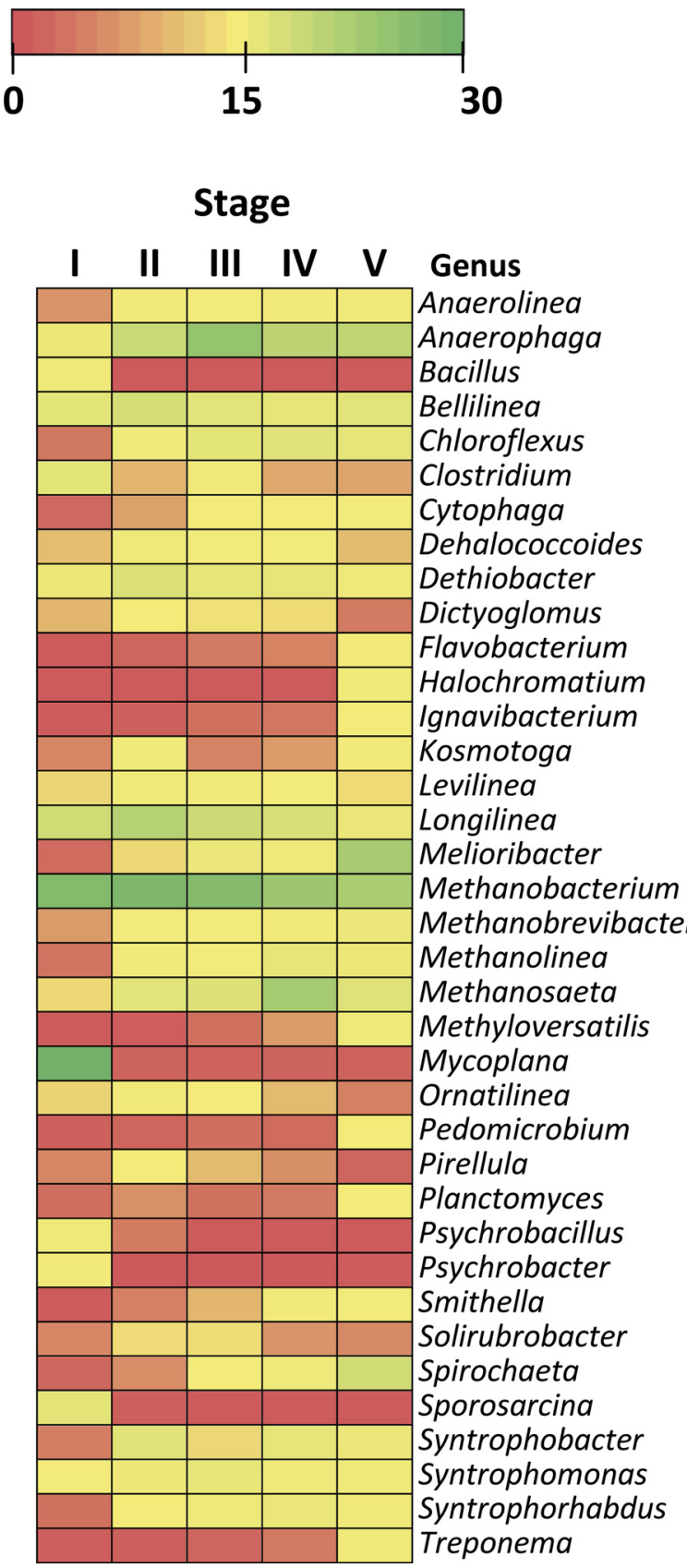

Fig. 4. Heat map of abundance dynamics for each genera at different ASBR operational.

stages. Only genera having a relative abundance $\geq 0.5 \%$ in at least one operational stage are represented.

by the genera Bellilinea (3.7-7.4\%), Longilinea (2.5-14.3\%), Anaerophaga (2.1-22.7\%) and Methanobacterium (16-29\%). Bellilinea and Longilinea are filamentous fermenters that produce volatile fatty acids. They lack the ability to use phenol as carbon source (Yamada et al., 2007) and it is suggested that they may be relevant to maintain the structure of granules in the anaerobic sludge (Yamada et al., 2005), an essential feature needed to work properly in SBR type reactors. On the other hand Anaerophaga is a strict anaerobe fermenter and its presence has been reported previously in microcosms enriched with benzoate (Herrmann et al., 2008) an intermediate compound produced in the anaerobic phenol degradation (Ju and Zhang, 2014), thus Anaerophaga could be using (at least) part of the benzoate generated as carbon source during the phenol degradation process.

As can be seen in Fig. 4, the increase of phenol concentration negatively affected the abundances of Dethiobacter, Longilinea and $\mathrm{Me}$ thanobacterium. All these three genera reducted their abundances to the minimum at the highest phenol concentration. A drop in members belonging to the core group could be one of the causes for performance impairment at this operational stage. As can be noted in the heat-map, the abatement in Methanobacterium abundance was compensated by a raise of Methanolinea and Methanobrevibacter, both hydrogenotrophic methanogens that share the same ecological function as Methanobacterium (i.e. hydrogenotrophic methanogenesis) and have been found in the same ecological niches (Yu et al., 2015; Martin Vincent et al., 2018; Prajapat et al., 2019). Abundance changes of co-ocurring archaeal members sharing the same function is caused by an environmental condition that favors the growth of one archaeal member over another. In this case, phenol concentration increase fauvored the growth of Methanolinea and Methanobrevibacter over Methanobacterium. Martin Vincent et al. (2018) reported that during an increase in organic loading in a methanogenic digester Methanobrevibacter increased its relative abundance over Methanobacterium. The latter suggests that the increase in organic load caused by a phenol concentration increment in the ASBR promoted the growth of Methanobrevibacter as well as Methanolinea.

\subsection{Correlations between microorganisms, bamA gene and performance} parameters

A principal component analysis was performed in order to visualize how changes in feeding phenol concentration affects the microbial community structure variability during the different operational stages in ASBR (Fig. 5). In the PCA plot each sample point has an specific position based on its particular genera abundance profile. This position was represented as circles whose size was proportional to the inlet phenol concentration applied to each operational stage. As can be noted, PC1 (X axis) and PC2 (Y axis) explains a great part of the samples variability (47 \% and $33 \%$, respectively). In addition, performance and environmental variables were represented as arrows, whose direction and length indicate to which sample the increase of this variable is explaining the microbial abundance patterns and the magnitude of that variable in explaining the microbial profiles variation, respectively. Based on the aforementioned, it is possible to observe that phenol concentration (PC) is related with the $\mathrm{X}$ axis principal component which means that microbial community structure was shaped at a great extent by the change of phenol feeding concentration. Genera correlated significantly with a specific variable is presented in Table 2 and were also plotted in the PCA. Significant positive correlations between the abundance of bamA gene with abundances of Cytophaga and Smithella were observed. These could mean that (i) they are directly involved in phenol degradation (either through bamA pathway, or another gene not targeted in our assay) or (ii) they are indirectly related for example through consumption of by-products of phenol degradation. Althought there is no information reported regarding the metabolic capacity of Smithella to degrade aromatic compounds, this genus is capable of syntrophically oxidize butyrate and propionate to acetate (Zhang et al., 2017) supporting the hypothesis (ii) of indirect relationship with phenol degraders. On the other hand, Cytophaga have been found in anaerobic reactors treating trichlorophenol (Collins et al., 2005) and clones belonging to this genus have been reported to be involved in polyaromatic hydrocarbon degradation under methanogenic conditions (Braun et al., 2015). Based on this and knowing that Cytophaga members harbour the bamA gene (by consulting Kyoto Encyclopedia of Genes and Genome) (Kanehisa and Goto (2000)), we infer that Cytophaga might be a direct phenol degrader.

Analysis between reactor parameters and microorganisms reveals that there are six genera that correlated positively with phenol concentration and ten with degradation time (Table 2). Of these, 


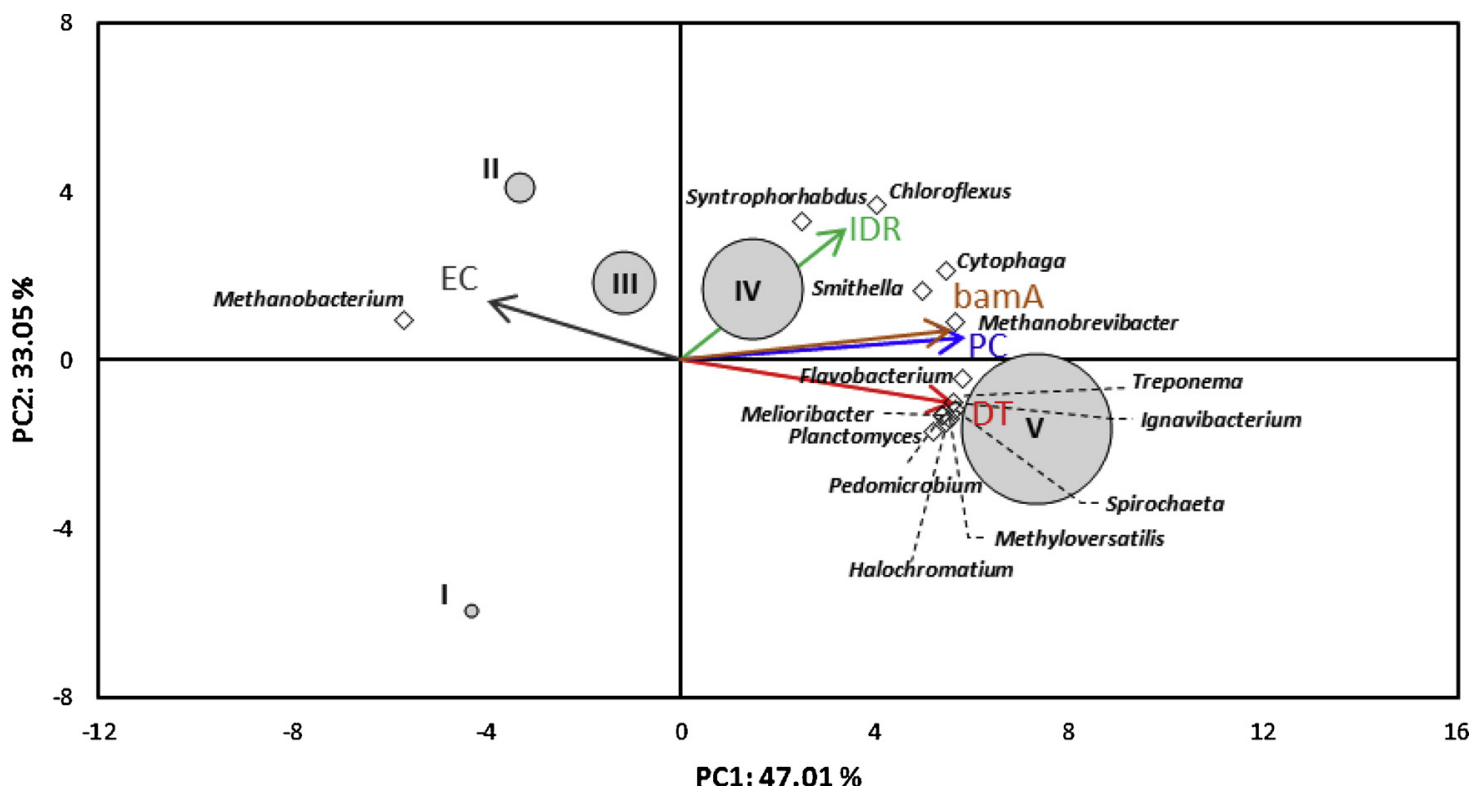

Fig. 5. Principal component analysis of the microbial structure distribution at genus level and correlations with bamA gene abundance, phenol concentration (PC) and the performance parameters; Elimination capacity (EC), Initial degradation rate (IDR) and degradation time (DT). For each operational stage, the circle size is proportional to feeding phenol concentration. Genera that correlated significantly with one or more variables were presented in the plot together with their specific positions denoted by diamonds.

Table 2

Pearson correlation coefficients (r) between significant correlated genera and Initial degradation rate (IDR), degradation time (DT) (performance variables), phenol concentration (PC) (environmental variable) and bamA gene (biological variable). The p-value is indicated: *<0.05, **< 0.01

\begin{tabular}{|c|c|c|c|c|}
\hline \multirow[b]{3}{*}{ Genus } & \multicolumn{3}{|c|}{ Variables } & \multirow{3}{*}{$\begin{array}{l}\text { Biological } \\
\text { bamA }\end{array}$} \\
\hline & \multicolumn{2}{|c|}{ Performance } & \multirow{2}{*}{$\begin{array}{l}\text { Environmental } \\
\text { PC }\end{array}$} & \\
\hline & IDR & DT & & \\
\hline Chloroflexus & 0.957 * & 0.458 & 0.771 & 0.844 \\
\hline Cytophaga & 0.782 & 0.802 & $0.955^{*}$ & $0.953^{*}$ \\
\hline Flavobacterium & 0.413 & $0.992 * *$ & $0.941^{*}$ & 0.862 \\
\hline Halochromatium & 0.113 & $0.982 * *$ & 0.802 & 0.678 \\
\hline Ignavibacterium & 0.297 & $1.000 * *$ & $0.897^{*}$ & 0.799 \\
\hline Melioribacter & 0.198 & $0.995^{* *}$ & 0.845 & 0.732 \\
\hline Methanobacterium & -0.596 & -0.875 & $-0.962 * *$ & $-0.946^{*}$ \\
\hline Methanobrevibacter & 0.411 & $0.960 * *$ & $0.919^{*}$ & 0.826 \\
\hline Methyloversatilis & 0.241 & $0.995^{* *}$ & 0.873 & 0.769 \\
\hline Pedomicrobium & 0.187 & $0.994 * *$ & 0.841 & 0.725 \\
\hline Planctomyces & 0.107 & $0.960 * *$ & 0.786 & 0.650 \\
\hline Smithella & $0.885^{*}$ & 0.625 & $0.902 *$ & $0.956^{*}$ \\
\hline Spirochaeta & 0.295 & $0.994 * *$ & $0.899^{*}$ & 0.804 \\
\hline Syntrophorhabdus & $0.983^{* *}$ & 0.118 & 0.541 & 0.683 \\
\hline Treponema & 0.212 & $0.992 * *$ & 0.858 & 0.750 \\
\hline DT & 0.296 & - & $0.896 *$ & 0.798 \\
\hline PC & 0.683 & $0.896^{*}$ & - & $0.980^{* *}$ \\
\hline bamA & 0.799 & 0.798 & $0.980 * *$ & - \\
\hline
\end{tabular}

Flavobacterium, Ignavibacterium, Spirochaeta and Methanobrevibacter had positive correlations with both parameters. Ignavibacterium was found to be a dominant aniline-degrader in methanogenic microcosm (Sun et al., 2015). Accordingly, this genus has the metabolic machinery to degrade monoaromatic compounds and, based on these results, the capability to tolerate high phenol concentrations. No aromatic degrading capacity was reported for the other genera. However, spirochaetal organisms were found in granular sludge of an EGSB-AF reactor treating $50 \mathrm{mg} \mathrm{L}^{-1}$ of trichlorophenol and were capable to tolerate the presence of this highly toxic compound (Collins et al., 2005) thus, it is expected that members of Spirochaeta genus are also able to cope with high phenol concentrations. On the other hand, higher degradation time in ASBR observed in stage $\mathrm{V}$ indicate that microbial members positively correlated with these variables were able to maintain the anaerobic digestion process stable (due to their capacity to tolerate high phenol concentration) but less efficiently either because a partial inhibition phenomenon or lower total degradation activity of the microorganisms which leads to display a higher degradation time. Correlation tests also showed that the genera Syntrophorhabdus, Chloroflexus and Smithella (maximum abundances at stage IV) have a significant positive correlation with the initial degradation rate. Syntrophorhabdus was widely reported in methanogenic systems treating phenolic compounds like phenol and p-cresol (Chen et al., 2009; Levén and Schnürer, 2010; Ju and Zhang, 2014; Na et al., 2016; Franchi et al., 2018a). Ju and Zhang (2014) reported the presence of Syntrophorhabdus in two methanogenic batch reactors treating phenol concentrations between 400 and $1000 \mathrm{mg} \mathrm{L}^{-1}$ displaying different degradation rates and suggested that a higher proportion of this microorganism could explain the higher rate of one reactor. At archaeal level, Methanobacterium showed a significant negative correlation with phenol concentration while Methanobrevibacter had a positive correlation with that parameter. Therefore, the concentration of this compound has a negative linear effect on the growth of Methanobacterium and, conversely, promotes in a linear manner the abundance of Methanobrevibacter. One possible explanation of this result, could be the presence of a competition relationship between these archaeal members, a phenomenon which offen occurs in closely related OTUs (both genus belongs to Methanobacteriaceae family) requiring similar resources for growth (i.e. carbon dioxide and hydrogen) (Wu et al., 2016). According to this, the phenol concentration increment, could be a relevant environmental variable in promoting the competition strength of Methanobrevibacter to the detriment of Methanobacterium. On the other hand, although $\mathrm{Me}$ thanolinea and Methanosaeta had positives correlations with initial degradation rate of ASBR the p-values of these correlations were just above the significance threshold (0.052 and 0.054, respectively). Despite this, our results show that the abundance increase of these archaeal members tends to improve the phenol degradation performance in a linear manner. The theorical reason of this trend could be explained first by an increase of the hydrogen scavenging capacity of the system due to a higher abundance of Methanolinea thus favouring Syntrophorhabdus degrading activity and secondly by an increase in the acetate consumer Methanosaeta which would be contributing to prevent 
the ASBR acidification. Notably, two paralel metabolic pathways may be co-occuring during the stage with highest efficiency, which suggest a positive synergic contribution of these archaeal members to the process. These results agree with our previous findings regarding the positive interactions (cooperation) between Syntrophorhabdus, Methanosaeta and hydrogenotrophic archaeas in a context of anaerobic digestion of phenolic compounds (Franchi et al., 2018b).

\section{Conclusions}

The increase of phenol concentration at more than $800 \mathrm{mg} \mathrm{L}^{-1}$ in ASBR system triggered a performance impairment on degradation process that was associated with an abundance reduction of a core group of microorganisms. At $800 \mathrm{mg} \mathrm{L}^{-1}$ of phenol, the degradation performance of ASBR reached its maximum in correspondence with highest abundances of Syntrophorhabdus, Chloroflexus, Smithella, Methanolinea and Methanosaeta which in turn were positively correlated with the initial degradation rate, indicating that the synergistic growth of these microorganisms promoted a better performance of the anaerobic degradation of phenol in the system. On the other hand, bamA gene dynamics showed that aromatic degraders targeted by the qPCR assay were accumulating through the process and correlated possitively with inlet feeding phenol concentration, suggesting that bamA gene quantification could be a useful monitoring variable capable to describe the growth progression of phenol degrading bacteria.

\section{Author contributions}

Author 1: Oscar Franchi
Collected the data
Performed the analysis
Wrote the paper
Author 2: Rolando Chamy
Conceived and designed the analysis
Author 3: Léa Cabrol
Performed the analysis
Author 4: Francisca Rosenkranz
Conceived and designed the analysis
Collected the data
Contributed data or analysis tools

\section{Declaration of Competing Interest}

The authors declare that they have no known competing financial interests or personal relationships that could have appeared to influence the work reported in this paper.

\section{Acknowledgements}

This research was funded by CONICYT Project 781302010 and FONDECYT Project 1151161 from CONICYT - CHILE.

\section{References}

Almendariz, F.J., Meraz, M., Olmos, A.D., Monroy, O., 2005. Phenolic refinery wastewater biodegradation by an expanded granular sludge bed reactor. Water Sci. Technol. 52 (1-2), 391-396.

APHA, 1995. Methods for Examination of Water and Wastewater, nineteen ${ }^{\text {th }}$ ed.

American Public Health Association/American Water Works Association/Water Environment Federation, Washington, DC, USA.

Braun, F., Hamelin, J., Bonnafous, A., Delgenès, N., Steyer, J.P., Patureau, D., 2015 Similar PAH fate in anaerobic digesters inoculated with three microbial communities accumulating either volatile fatty acids or methane. PLoS One 10 (4), e0125552.

Cabezas, A., de Araujo, J.C., Callejas, C., Galès, A., Hamelin, J., Marone, A., Etchebehere, C., 2015. How to use molecular biology tools for the study of the anaerobic digestion process? Rev. Environ. Sci. Biotechnol. 14 (4), 555-593.

Carballa, M., Regueiro, L., Lema, J.M., 2015. Microbial management of anaerobic digestion: exploiting the microbiome-functionality nexus. Curr. Opin. Biotechnol. 33, 103-111.

Chapleur, O., Madigou, C., Civade, R., Rodolphe, Y., Mazéas, L., Bouchez, T., 2016. Increasing concentrations of phenol progressively affect anaerobic digestion of cellulose and associated microbial communities. Biodegradation 27 (1), 15-27.

Chen, C.L., Wu, J.H., Liu, W.T., 2008a. Identification of important microbial populations in the mesophilic and thermophilic phenol-degrading methanogenic consortia. Water Res. 42 (8), 1963-1976.

Chen, Y., Cheng, J.J., Creamer, K.S., 2008b. Inhibition of anaerobic digestion process: a review. Bioresour. Technol. 99 (10), 4044-4064.

Chen, C.L., Wu, J.H., Tseng, I.C., Liang, T.M., Liu, W.T., 2009. Characterization of active microbes in a full-scale anaerobic fluidized bed reactor treating phenolic wastewater. Microbes Environ. 24 (2), 144-153.

Collins, G., Foy, C., McHugh, S., O'Flaherty, V., 2005. Anaerobic treatment of 2, 4, 6trichlorophenol in an expanded granular sludge bed-anaerobic filter (EGSB-AF) bioreactor at 15 C. FEMS Microbiol. Ecol. 53 (1), 167-178.

De Vrieze, J., Regueiro, L., Props, R., Vilchez-Vargas, R., Jáuregui, R., Pieper, D.H., Carballa, M., 2016. Presence does not imply activity: DNA and RNA patterns differ in response to salt perturbation in anaerobic digestion. Biotechnol. Biofuels 9 (1), 244.

DeSantis, T.Z., Hugenholtz, P., Larsen, N., Rojas, M., Brodie, E.L., Keller, K., Andersen, G.L., 2006. Greengenes, a chimera-checked 16S rRNA gene database and workbench compatible with ARB. Appl. Environ. Microbiol. 72 (7), 5069-5072.

Eichorst, S.A., Varanasi, P., Stavila, V., Zemla, M., Auer, M., Singh, S., Singer, S.W., 2013. Community dynamics of cellulose-adapted thermophilic bacterial consortia. Environ. Microbiol. 15 (9), 2573-2587.

Fang, H.H.P., Liu, Y., Ke, S.Z., Zhang, T., 2004. Anaerobic degradation of phenol in wastewater at ambient temperature. Trends in Sustain. Prod. 49 (1), 95-102.

Franchi, O., Rosenkranz, F., Chamy, R., 2018a. Key microbial populations involved in anaerobic degradation of phenol and p-cresol using different inocula. Electron. J. Biotechnol. 35, 33-38.

Franchi, O., Bovio, P., Ortega-Martínez, E., Rosenkranz, F., Chamy, R., 2018b. Active and total microbial community dynamics and the role of functional genes bamA and mcrA during anaerobic digestion of phenol and p-cresol. Bioresour. Technol. 264, 290-297.

Fuchs, G., 2008. Anaerobic metabolism of aromatic compounds. Ann. N. Y. Acad. Sci. 1125 (1), 82-99.

Hanreich, A., Schimpf, U., Zakrzewski, M., Schluter, A., Benndorf, D., Heyer, R., Rapp, E. Puhler, A., Reichl, U., Klocke, M., 2013. Metagenome and metaproteome analyses of 610 microbial communities in mesophilic biogas-producing anaerobic batch fermentations 611 indicate concerted plant carbohydrate degradation. Syst. Appl. Microbiol. 36 (5), 330-338.

Hernandez, J.E., Edyvean, R.G.J., 2008. Inhibition of biogas production and biodegradability by substituted phenolic compounds in anaerobic sludge. J. Hazard. Mater. 160 (1), 20-28.

Hernandez, C.H., Limam, I., Desmond, E., Bouchez, T., Mazeas, L., 2013. Anaerobic biodegradation of 13C6-phenol: analysis of bacteria population involved in two different degradation kinetics. In: In 13th World Congress on Anaerobic Digestion: Recovering (Bio) Resources for the World. (Pp. 4-P).

Herrmann, S., Kleinsteuber, S., Neu, T.R., Richnow, H.H., Vogt, C., 2008. Enrichment of anaerobic benzene-degrading microorganisms by in situ microcosms. FEMS Microbiol. Ecol. 63 (1), 94-106.

Ju, F., Zhang, T., 2014. Novel microbial populations in ambient and mesophilic biogasproducing and phenol-degrading consortia unravelled by high-throughput sequencing. Microb. Ecol. 68 (2), 235-246.

Kanehisa, M., Goto, S., 2000. KEGG: kyoto encyclopedia of genes and genomes. Nucleic Acids Res. 28 (1), 27-30.

Kazy, S., Monier, A., Alvarez, P., 2010. Assessing the correlation between anaerobic toluene degradation activity and bssA concentrations in hydrocarbon-contaminated aquifer material. Biodegradation 21, 793-800.

Kuntze, K., Shinoda, Y., Moutakki, H., McInerney, M.J., Vogt, C., Richnow, H.H., Boll, M., 2008. 6-Oxocyclohex-1-ene-1-carbonyl-coenzyme A hydrolases from obligatory anaerobic bacteria: characterization and identification of its gene as a functional marker for aromatic compounds degrading anaerobes. Environ. Microbiol. 10 (6), $1547-1556$.

Kuntze, K., Vogt, C., Richnow, H.H., Boll, M., 2011. Combined application of PCR-based functional assays for the detection of aromatic-compound-degrading anaerobes. Appl. Environ. Microbiol. 77 (14), 5056-5061.

Laempe, D., Jahn, M., Fuchs, G., 1999. 6-Hydroxycyclohex-1-ene-1-carbonyl-CoA dehydrogenase and 6-oxocyclohex-1-ene-1-carbonyl-CoA hydrolase, enzymes of the benzoyl-CoA pathway of anaerobic aromatic metabolism in the denitrifying bacterium Thauera aromatica. Eur. J. Biochem. 263 (2), 420-429.

Lakshmi, M.B., Muthukumar, K., Velan, M., 2013. Optimization of minimal salt medium for efficient phenanthrene biodegradation by Mycoplana sp. MVMB2 isolated from petroleum contaminated soil using factorial design experiments. CLEAN- Soil, Air, Water 41, 51-59.

Levén, L., Schnürer, A., 2010. Molecular characterisation of two anaerobic phenol-degrading enrichment cultures. Int. Biodeterior. Biodegradation 64 (6), 427-433.

Levén, L., Nyberg, K., Schnürer, A., 2012. Conversion of phenols during anaerobic digestion of organic solid waste-a review of important microorganisms and impact of temperature. J. Environ. Manage. 95, S99-S103.

Li, X.K., Ma, K.L., Meng, L.W., Zhang, J., Wang, K., 2014. Performance and microbial community profiles in an anaerobic reactor treating with simulated PTA wastewater: 
from mesophilic to thermophilic temperature. Water Res. 61, 57-66.

Madigou, C., Poirier, S., Bureau, C., Chapleur, O., 2016. Acclimation strategy to increase phenol tolerance of an anaerobic microbiota. Bioresour. Technol. 216, 77-86.

Martin Vincent, N., Wei, Y., Zhang, J., Yu, D., Tong, J., 2018. Characterization and dynamic shift of microbial communities during start-up, overloading and steady-state in an anaerobic membrane bioreactor. Int. J. Environ. Res. Public Health 15 (7), 1399.

Na, J.G., Lee, M.K., Yun, Y.M., Moon, C., Kim, M.S., Kim, D.H., 2016. Microbial community analysis of anaerobic granules in phenol-degrading UASB by next generation sequencing. Biochem. Eng. J. 112, 241-248.

Oka, A.R., Phelps, C.D., Zhu, X., Saber, D.L., Young, L.Y., 2011. Dual biomarkers of anaerobic hydrocarbon degradation in historically contaminated groundwater. Environ. Sci. Technol. 45 (8), 3407-3414.

Poirier, S., Bize, A., Bureau, C., Bouchez, T., Chapleur, O., 2016. Community shifts within anaerobic digestion microbiota facing phenol inhibition: Towards early warning microbial indicators? Water Res. 100, 296-305.

Prajapat, G., Jain, S., Agrawal, A., 2019. Microbial diversity and dynamics in hydrocarbon Resource environments. Microbial Diversity in Ecosystem Sustainability and Biotechnological Applications. Springer, Singapore, pp. 533-571.

Pylro, V.S., Morais, D.K., Kalks, K.H.M., Roesch, L.F.W., Hirsch, P.R., Tótola, M.R., Yotoko, K., 2016. Misguided phylogenetic comparisons using DGGE excised bands may contaminate public sequence databases. J. Microbiol. Methods 126, 18-23.

Qiu, Y.L., Hanada, S., Ohashi, A., Harada, H., Kamagata, Y., Sekiguchi, Y., 2008. Syntrophorhabdus aromaticivorans gen. nov., sp. nov., the first cultured anaerobe capable of degrading phenol to acetate in obligate syntrophic associations with hydrogenotrophic methanogen. Appl. Environ. Microbiol. 74 (7), 2051-2058.

Rafrafi, Y., Trably, E., Hamelin, J., Latrille, E., Meynial-Salles, I., Benomar, S., Steyer, J.P., 2013. Sub-dominant bacteria as keystone species in microbial communities producing bio-hydrogen. Int. J. Hydrogen Energy 38 (12), 4975-4985.

Regueiro, L., Lema, J.M., Carballa, M., 2015. Key microbial communities steering the functioning of anaerobic digesters during hydraulic and organic overloading shocks. Bioresour. Technol. 197, 208-216.

Rosenkranz, F., Cabrol, L., Carballa, M., Donoso-Bravo, A., Cruz, L., Ruiz-Filippi, G., Chamy, R., Lema, J.M., 2013. Relationship between phenol degradation efficiency and microbial community structure in an anaerobic SBR. Water Res. 47 (17), 6739-6749.

Shin, S.G., Koo, T., Lee, J., Han, G., Cho, K., Kim, W., Hwang, S., 2016. Correlations between bacterial populations and process parameters in four full-scale anaerobic digesters treating sewage sludge. Bioresour. Technol. 214, 711-721.

Smalley, N.E., Taipale, S., De Marco, P., Doronina, N.V., Kyrpides, N., Shapiro, N., Kalyuzhnaya, M.G., 2015. Functional and genomic diversity of methylotrophic Rhodocyclaceae: description of the new species Methyloversatilis discipulorum sp. Nov. Int. J. Syst. Evol. Microbiol ijs-0.

Smith, K.S., Ingram-Smith, C., 2007. Methanosaeta, the forgotten methanogen? Trends Microbiol. 15 (4), 150-155.

Sun, W., Sun, X., Cupples, A.M., 2014. Presence, diversity and enumeration of functional genes (bssA and $\operatorname{bam} A$ ) relating to toluene degradation across a range of redox conditions and inoculum sources. Biodegradation 25 (2), 189-203.
Sun, W., Li, Y., McGuinness, L.R., Luo, S., Huang, W., Kerkhof, L.J., Fennell, D.E., 2015. Identification of anaerobic aniline-degrading bacteria at a contaminated industrial site. Environ. Sci. Technol. 49 (18), 11079-11088.

Tartakovsky, B., Manuel, M.F., Beaumier, D., Greer, C.W., Guiot, S.R., 2001. Enhanced selection of an anaerobic pentachlorophenol-degrading consortium. Biotechnol. Bioeng. 73 (6), 476-483.

Veeresh, G.S., Kumar, P., Mehrotra, I., 2005. Treatment of phenol and cresols in upflow anaerobic sludge blanket (UASB) process: a review. Water Res. 39 (1), 154-170.

Wang, Y., Qian, P.Y., 2009. Conservative fragments in bacterial 16S rRNA genes and primer design for $16 \mathrm{~S}$ ribosomal DNA amplicons in metagenomic studies. PLoS One 4 (10), e7401.

Wang, Z., Yang, Y., Dai, Y., Xie, S., 2015. Anaerobic biodegradation of nonylphenol in river sediment under nitrate-or sulfate-reducing conditions and associated bacterial community. J. Hazard. Mater. 286, 306-314.

Wirth, B., Krebs, M., Andert, J., 2015. Anaerobic degradation of increased phenol concentrations in batch assays. Environ. Sci. Pollut. Res. Int. 22 (23), 19048-19059.

Wong, R.G., Wu, J.R., Gloor, G.B., 2016. Expanding the UniFrac toolbox. PLoS One 11 (9), e0161196.

Wu, L., Yang, Y., Chen, S., Zhao, M., Zhu, Z., Yang, S., He, Q., 2016. Long-term successional dynamics of microbial association networks in anaerobic digestion processes. Water Res. 104, 1-10.

Xiong, S., Li, X., Chen, J., Zhao, L., Zhang, H., Zhang, X., 2015. Crude oil degradation by bacterial consortia under four different redox and temperature conditions. Appl. Microbiol. Biotechnol. 99 (3), 1451-1461.

Yamada, T., Sekiguchi, Y., Imachi, H., Kamagata, Y., Ohashi, A., Harada, H., 2005. Diversity, localization, and physiological properties of filamentous microbes belonging to Chloroflexi subphylum I in mesophilic and thermophilic methanogenic sludge granules. Appl. Environ. Microbiol. 71 (11), 7493-7503.

Yamada, T., Imachi, H., Ohashi, A., Harada, H., Hanada, S., Kamagata, Y., Sekiguchi, Y., 2007. Bellilinea Caldifistulae gen. nov., Sp Nov and Longilinea arvoryzae gen. nov., Sp nov., Strictly Anaerobic, Filamentous Bacteria of the Phylum Chloroflexi isolated From Methanogenic Propionate-degrading.

Yu, Y., Kim, J., Hwang, S., 2006. Use of real-time PCR for group-specific quantification of aceticlastic methanogens in anaerobic processes: population dynamics and community structures. Biotechnol. Bioeng. 93 (3), 424-433.

Yu, B., Zhang, D., Shan, A., Lou, Z., Yuan, H., Huang, X., Zhu, N., 2015. Methane-rich biogas production from waste-activated sludge with the addition of ferric chloride under a thermophilic anaerobic digestion system. RSC Adv. 5 (48), 38538-38546.

Zakrzewski, M., Goesmann, A., Jaenicke, S., Jünemann, S., Eikmeyer, F., Szczepanowski, R., Al-Soud, W.A., Sørensen, S., Pühler, A., Schlüter, A., 2012. Profiling of the metabolically active community from a production-scale biogas plant by means of highthroughput metatranscriptome sequencing. J. Biotechnol 158 (4), 248-258.

Zhang, T., Ke, S.Z., Liu, Y., Fang, H.P., 2005. Microbial characteristics of a methanogenic phenol-degrading sludge. Water Sci. Technol. 52 (1), 73-78.

Zhang, J., Mao, L., Zhang, L., Loh, K.C., Dai, Y., Tong, Y.W., 2017. Metagenomic insight into the microbial networks and metabolic mechanism in anaerobic digesters for food waste by incorporating activated carbon. Sci. Rep. 7 (1), 11293. 